\title{
Near-infrared fluorescence angiography for intra-operative assessment of pedicled omentoplasty for filling of a pelvic cavity: a pilot study
}

\author{
M. D. Slooter ${ }^{1} \cdot$ R. D. Blok ${ }^{1,2}$ - D. D. Wisselink ${ }^{1} \cdot$ C. J. Buskens ${ }^{1} \cdot$ W. A. Bemelman ${ }^{1} \cdot$ P. J. Tanis ${ }^{1} \cdot$ R. Hompes $^{1,3}$
}

Received: 13 March 2019 / Accepted: 19 July 2019 / Published online: 21 August 2019

(c) The Author(s) 2019

\begin{abstract}
Background During creation of a pedicled omentoplasty, blood flow to segments of the omentum might become compromised. If unrecognized, this can lead to omental necrosis. The purpose of this study was to investigate the potential added intra-operative value of the use of fluorescence angiography (FA) with indocyanine green (ICG) to assess omental perfusion. Methods All consecutive patients undergoing a pedicled omentoplasty in a 6-month period (April 1 2018-October 12018 ) in a University hospital were included. The primary outcome was change in management due to FA. Secondary outcomes included the amount of additionally resected omentum, added surgical time, and quantitative fluorescent values (time to fluorescent enhancement, contrast quantification).

Results Fifteen patients had pelvic surgery with omentoplasty and FA. Change in management occurred in 12 patients (80\%) and consisted of resecting a median of $44 \mathrm{~g}$ (range 12-198 g) of poorly perfused omental areas that were not visible by conventional white light. The median added surgical time for the use of FA and subsequent management was 8 min (range 3-39 min). The first fluorescent signal in the omental tissue appeared after a median of $20 \mathrm{~s}$ (range 9-37 s) after injection of ICG. The median signal-to-baseline ratio was 23.7 (interquartile range 12.2-29.7) in well perfused and 2.5 (interquartile range 1.7-4.0) in poorly perfused tissue.

Conclusions FA of a pedicled omentoplasty allows a real-time assessment of omental perfusion and leads to change in management in $80 \%$ of the cases in this pilot study. These findings support the conduct of larger studies to determine the impact on patient outcome in this setting.
\end{abstract}

Keywords Omentoplasty $\cdot$ Fluorescence angiography $\cdot$ Indocyanine green (ICG) $\cdot$ Rectal surgery $\cdot$ Pelvic filling

\section{Introduction}

Application of omentoplasty is a well-established option for filling of a presacral cavity after both primary abdominoperineal resection [1] and more complex salvage surgery

R. Hompes

r.hompes@amsterdamumc.nl

1 Department of Surgery, Amsterdam UMC, University of Amsterdam, Meibergdreef 9, 1105 AZ Amsterdam, The Netherlands

2 LEXOR, Center for Experimental and Molecular Medicine, Oncode Institute, Cancer Center Amsterdam, Amsterdam UMC, University of Amsterdam, Meibergdreef 9, 1105 AZ Amsterdam, The Netherlands

3 Department of Surgery, Amsterdam UMC, University of Amsterdam, G4, Post box 22660, 1100 DD Amsterdam, The Netherlands
[2-5]. Success of an omentoplasty depends on the adequacy of filling the pelvic cavity, determined by the omental volume and length. After full detachment from the transverse colon, additional mobilization is often necessary. This can be achieved by creation of a pedicled omentoplasty on one of the gastroepiploic arteries. Adequate vascularization of the omental flap is guaranteed as the main trunks are connected via several collateral arches. Nevertheless, intra-operative partial omental flap necrosis has been reported to occur in up to $10 \%$ of cases [6], and post-operative flap necrosis requiring reoperation has been reported in an additional 2-4\% [6-8]. This suggests that blood flow to segments of the omentum might become compromised after flap creation, implying the need for intra-operative evaluation of omental perfusion with higher sensitivity than conventional white light assessment. 
Fluorescence angiography (FA) using indocyanine green (ICG) has emerged as a promising technique for real-time intra-operative evaluation of perfusion [9]. After intravenous administration, ICG rapidly binds to plasma proteins and is transported with minimal leakage to the interstitium, making ICG an ideal marker for perfusion. FA using ICG of the omentum has been described during a free omental lymphatic transplant [10] and a pedicled omental flap to wrap the cervical esophagogastric anastomosis [11]. However, the possible added value of FA for assessing omental perfusion of a pedicled omentoplasty for pelvic filling has not been evaluated so far.

Therefore, the aim of this single-center pilot study was to investigate the potential intra-operative value of the use of FA in patients who underwent omentoplasty for filling of a pelvic cavity.

\section{Materials and methods}

\section{Patient selection}

The Amsterdam University Medical Center (UMC) is a tertiary referral center for the treatment of complex pelvic sequelae of inflammatory bowel disease and treatment of pelvic malignancies. For this reason, a relatively high number of salvage procedures with (pedicled) omentoplasty are performed each year [3, 4]. All consecutive patients having a pedicled omentoplasty in a 6-month period from introduction of FA in April 12018 to October 1 2018, in the Amsterdam UMC, were prospectively recorded. The complex pelvic procedures were performed by three specialized colorectal surgeons.

Retrospective data extraction from electronic patient files included demographics, significant past medical history, operative details, and FA video files. Co-morbidities recorded were diabetes, pulmonary, and cardiovascular diseases.

The local ethics committee waived the need for written informed consent, because there was no burden for the patient and data were handled anonymously. Patients were informed about the study by letter, including an opt out form with stamped return envelope. Patients were given the opportunity to opt out within 4 weeks, after which consent to participation was assumed.

\section{Outcome measures}

The primary outcome was change in management due to FA. Secondary outcomes included quality of the technique, additionally excised omental fat (in grams), added surgical time (rounded to minutes), and quantitative fluorescent values (i.e., time to fluorescent enhancement and contrast quantification). Quality of the technique was deemed high if no technical failures occurred and the fluorescent signal was evident for decision making. Other outcomes included feasibility of the technique and safety profile (adverse events related to ICG).

\section{Procedure}

After creation of the pedicled omentoplasty, the perfusion was assessed by visual inspection, with the addition of palpation of feeding vessels in open procedures. Based on these findings, it was decided whether or not additional trimming was necessary. FA was then performed after injection of ICG $(0.1 \mathrm{mg} / \mathrm{kg} /$ bolus $)$ and time of injection was noted in the electronic patient file. FA was subjectively analyzed by the surgeon. If FA was inconsistent with the initial intended strategy and additional resection was deemed necessary, this was considered change in management. Subsequently, areas of the omentum with poor perfusion were resected accordingly. Imaging was performed by the PINPOINT Endoscopic Fluorescence Imaging System or the SPY Portable Handheld Imaging System (Stryker, Kalamazoo, MI, USA), Food and Drug Administration (FDA) - approved and European Conformity (CE)-marked systems for visualizing blood flow in (micro-)vessels, tissue, and organ perfusion during surgical procedures. The video file of omental FA was not routinely recorded within the patient file.

\section{Contrast quantification}

Images were subtracted from the video files. Signal-tobaseline ratios (SBR) of well perfused and poorly perfused tissue, based on subjective judgement, were calculated. The signal was assessed $30 \mathrm{~s}$ after fluorescent enhancement in the target tissue, and the baseline before enhancement. The SBR were measured using the ImageJ software (v 1.50i, National Institutes of Health, Bethesda,MD, USA). Contrastto-noise ratios (CNR) were calculated according to Tichauer et al. [12].

\section{Statistical analysis}

All categorical data are presented as number of cases and percentages, while continuous data are shown as either median and total range or interquartile range (IQR). To compare perfused to poorly perfused tissue, analysis of significance was performed through paired $t$ tests and $p<0.05$ was considered significant. Data were analyzed using the Statistical Package for Social Sciences (SPSS) of IBM Statistics, version 25.0. 


\section{Results}

\section{Baseline characteristics}

Fifteen patients were included in this study. The median age of the patients was 55 years (range 23-82 years) with a median body mass index of $27 \mathrm{~kg} / \mathrm{m}^{2}$ (range 20-42 kg/ $\mathrm{m}^{2}$ ) (Table 1). Six patients had surgery for severe medical refractory fistulizing anorectal Crohn's disease and nine for sequelae from previous treatment of a pelvic malignancy. Details of the surgical procedures are provided in Table 1. The omentoplasty was pedicled on the left gastroepiploic artery in 9 out of $15(60 \%)$ and on the right in 6 out of 15 $(40 \%)$ cases. Transmesocolic was the preferred route to the pelvis in most cases.

\section{Fluorescence angiography}

The use of FA was performed at least 60 min after the creation of the omentoplasty for optimal conventional white light assessment. A high-quality intra-operative ICG angiogram was achieved in all patients. Figure 1 shows an example of FA after creation of the omental pedicle. The use of FA led to a change in management in 12 out of 15 patients $(80 \%)$ (Table 2). In 12 patients, poorly perfused omental fat was excised on the adjusted demarcation line, removing a median amount of $44 \mathrm{~g}$ (range 12-198 g). For 11 procedures (4 video clips were not recorded), the median added surgical time was $8 \mathrm{~min}$ (range 3-39 min), including time for perfusion assessment and trimming of the omental flap. No adverse events related to ICG occurred.

\section{Contrast quantification}

In 10 procedures, the first fluorescent signal in the omental tissue appeared at a median $20 \mathrm{~s}$ (range 9-37 s) after injection of ICG. After first fluorescent enhancement, the demarcation line was clearly visible after median $12 \mathrm{~s}$ (range 7-22 s).

In 11 procedures, the difference between the SBR and CNR of perfused versus poorly perfused tissue significantly differed (Fig. 2). The median SBR was 23.7 (IQR 12.2-29.7) in well-perfused tissue and 2.5 (IQR 1.7-4.0) in poorly perfused tissue (Fig. 2a). Corresponding CNR was 34.0 (IQR 14.5-52.7) and 2.2 (IQR 0.7-3.2), respectively (Fig. 2b).

\section{Discussion}

This study illustrates the potential added intra-operative value of FA to assess omental perfusion after creation of a pedicled omentoplasty. In this study, we found a $80 \%$ change in management due to FA.
Table 1 Baseline characteristics and surgical procedures

\begin{tabular}{|c|c|}
\hline & FA $(N=15)$ \\
\hline Age, years & 55 (range 23-82) \\
\hline BMI, $\mathrm{kg} / \mathrm{m}^{2}$ & 27 (range $20-42$ ) \\
\hline \multicolumn{2}{|l|}{ Comorbidity } \\
\hline Diabetes mellitus & $3 / 15(20 \%)$ \\
\hline Pulmonary diseases & $1 / 15(6.7 \%)$ \\
\hline Cardiovascular diseases & $6 / 15(40 \%)$ \\
\hline \multicolumn{2}{|l|}{ Smoking } \\
\hline Yes & $3 / 15(20 \%)$ \\
\hline No & $12 / 15(80 \%)$ \\
\hline \multicolumn{2}{|l|}{ ASA } \\
\hline$<3$ & $8 / 15(53.3 \%)$ \\
\hline 3 & $7 / 15(46.7 \%)$ \\
\hline \multicolumn{2}{|l|}{ Primary disease } \\
\hline Crohn's disease & $6 / 15(40 \%)$ \\
\hline Rectal cancer & $8 / 15(53.3 \%)$ \\
\hline Cervical cancer & $1 / 15(6.7 \%)$ \\
\hline \multicolumn{2}{|l|}{ Prior treatment } \\
\hline Biologicals $<3$ months $^{\mathrm{a}}$ & $2 / 6(33.3 \%)$ \\
\hline Neoadjuvant (chemo)radiation ${ }^{\mathrm{b}}$ & $7 / 9(77.8 \%)$ \\
\hline \multicolumn{2}{|l|}{ Prior interventions } \\
\hline Abscess drainage & $4 / 15(26.7 \%)$ \\
\hline Ileo-/colostomy & $15 / 15(100 \%)$ \\
\hline LAR/Hartmann & $6 / 15(40 \%)$ \\
\hline APR & $1 / 15(6.7 \%)$ \\
\hline Re-do & $1 / 15(6.7 \%)$ \\
\hline EVAC & $3 / 15(20 \%)$ \\
\hline \multicolumn{2}{|l|}{ Indication surgery } \\
\hline Therapy refractory disease & $6 / 6(100 \%)$ \\
\hline Presacral sinus & $6 / 9(66.7 \%)$ \\
\hline Other $^{\mathrm{c}}$ & $3 / 9(33.3 \%)$ \\
\hline \multicolumn{2}{|l|}{ Surgical procedure } \\
\hline Intersphincteric proct(ocolec)tomy & $7 / 15(46.7 \%)$ \\
\hline Resection anastomosis & $5 / 15(33.3 \%)$ \\
\hline Debridement sinus & $7 / 15(46.7 \%)$ \\
\hline Total exenteration & $1 / 15(6.7 \%)$ \\
\hline Other & $1 / 15(6.7 \%)$ \\
\hline \multicolumn{2}{|l|}{ Abdominal approach } \\
\hline Laparoscopy & $12 / 15(80 \%)$ \\
\hline Laparotomy & $3 / 15(20 \%)$ \\
\hline \multicolumn{2}{|l|}{ Perineal approach } \\
\hline TAMIS & $14 / 15(93.3 \%)$ \\
\hline Open & $1 / 15(6.7 \%)$ \\
\hline \multicolumn{2}{|l|}{ Pedicled omentoplasty } \\
\hline Left gastroepiploic artery & $9 / 15(60 \%)$ \\
\hline Right gastroepiploic artery & $6 / 15(40 \%)$ \\
\hline \multicolumn{2}{|l|}{ Route to pelvic } \\
\hline Left paracolic gutter & $6 / 15(40 \%)$ \\
\hline Trans mesocolic, medial to colostomy & $8 / 15(53.3 \%)$ \\
\hline Supracolic, medial to colostomy & $1 / 15(6.7 \%)$ \\
\hline
\end{tabular}




\section{Table 1 (continued)}

BMI Body mass index, ASA American Society of Anesthesiologists Score, LAR Low anterior resection, APR Abdominoperineal resection, EVAC Endoscopic vacuum-assisted closure, TAMIS Transanal minimally invasive surgery

${ }^{a}$ The patients with Crohn's disease

${ }^{\mathrm{b}}$ The patients with malign diseases (rectal and cervical cancer)

${ }^{c}$ Namely: radiation necrosis with vesico- and rectovaginal fistulas, near circumferential anastomotic dehiscence with pelvic sepsis, or synchronous double tumor of colon/rectum, blow-out colon and abscess

The high rate of change in management due to devascularization is quite remarkable, as surgeons judge omental perfusion to be insufficient in approximately $10 \%$ of cases by means of conventional white light assessment [6]. This is also contradictory to the low incidence of post-operative omental necrosis requiring reoperation as reported in the current literature [6-8]. However, there is probably an important underreporting of necrosis as literature on omentoplasty solely concerns retrospective studies and describes incidental cases of omental necrosis that resulted in surgical reintervention. Small pieces of omentum that become ischemic are potentially overlooked or misdiagnosed. An ischemic tip of the omentum might not lead to
Table 2 Fluorescence angiography

\begin{tabular}{ll}
\hline & FA $(N=15)$ \\
\hline Change in management & $12 / 15(80 \%)$ \\
Additional excised tissue $(\mathrm{g})$ & $44(12-198)$ \\
Added surgical time (min) & $8(3-39)$ \\
Time of injection to first fluorescence (s) & $20(9-37)$ \\
Time of first fluorescence to demarcation line (s) & $12(7-22)$ \\
\hline
\end{tabular}

apparent clinical deterioration. But more likely, this leads to a pelvic fluid collection that is interpreted as a consequence of the underlying condition. If such an abscess is radiologically drained, the etiology is hard to determine.

Another explanation for the high rate of change in management is overtreatment: additional tissue might be resected without clinical relevance. Necrosis of small parts of omentum might not always lead to an abscess or wound healing problems. However, it is important to note that necrosis of small parts of omentum is more likely to lead to infectious problems in patients suffering from pelvic sepsis, in comparison to a primary clean-contaminated abdominoperineal resection for rectal cancer.

Another reason for the high rate of change in management in this study could be related to the inadequate

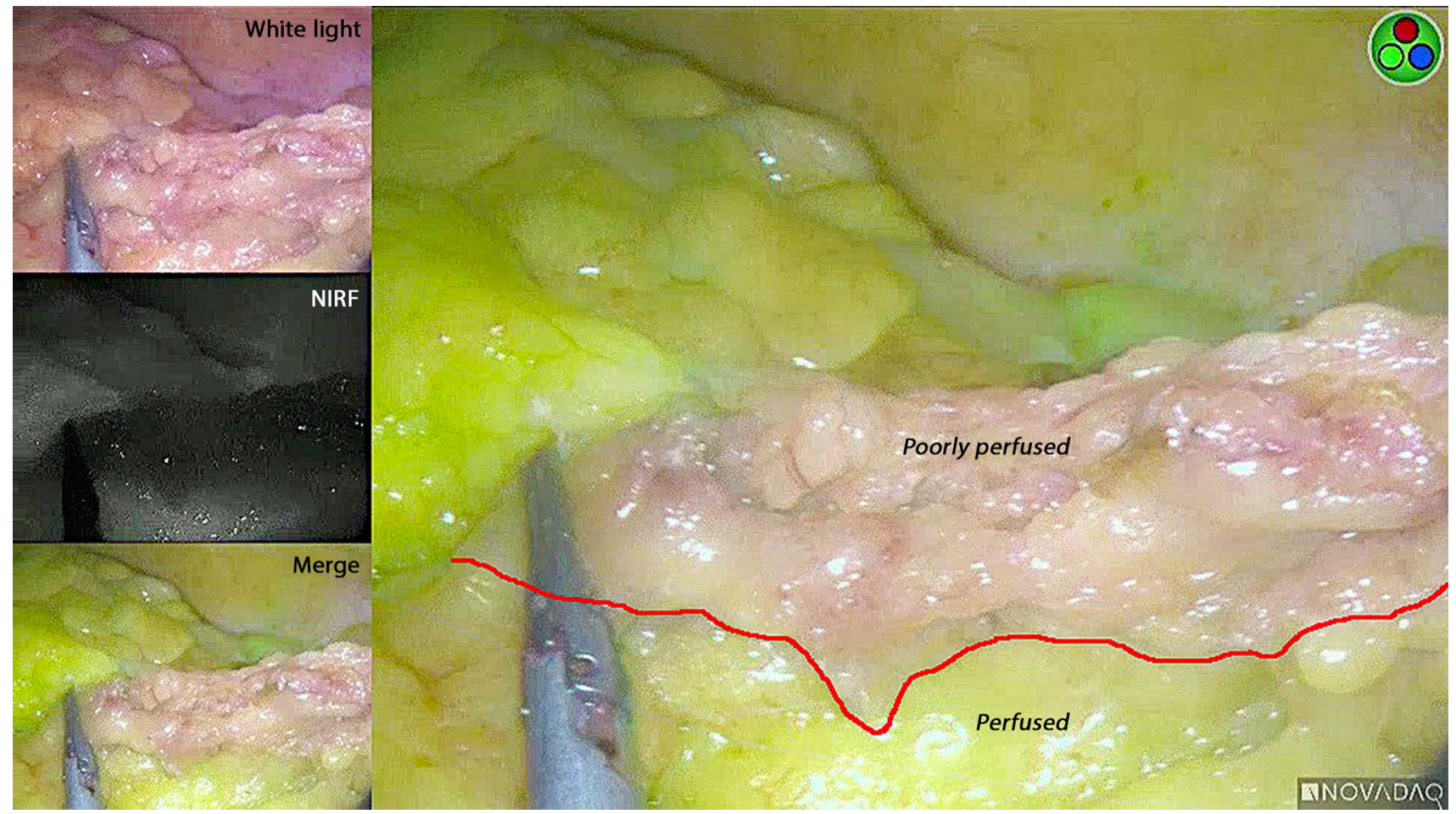

Fig. 1 An example of fluorescence angiography after a pedicled omental flap creation. White light is the standard view and shows no areas suspect for decreased perfusion. NIRF is the near-infrared fluorescent signal of ICG. Merge is the overlay of the white light and
NIRF, with the fluorescent signal displayed in pseudo green. The technique points out the areas that are perfused and poorly perfused. The red line demonstrates the demarcation line along which additional tissue was excised 
Fig. 2 Contrast quantification a signal-to-baseline ratio, $\mathbf{b}$ contrast-to-noise ratio

\section{a Signal-to-baseline ratio}

$\square$ Poorly perfused $\square$ Perfused

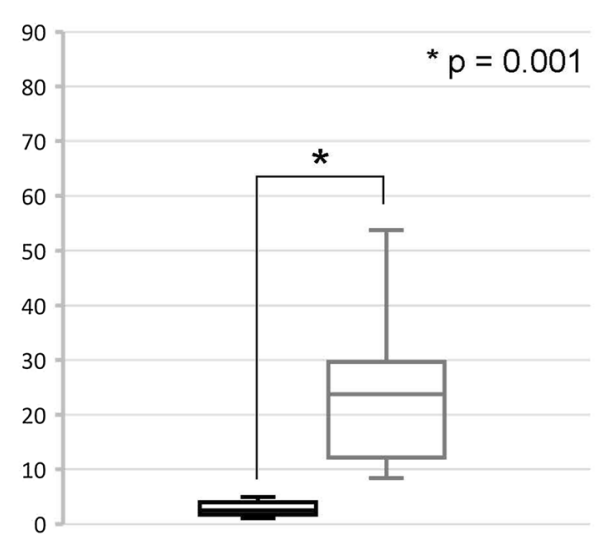

b Contrast-to-noise ratio

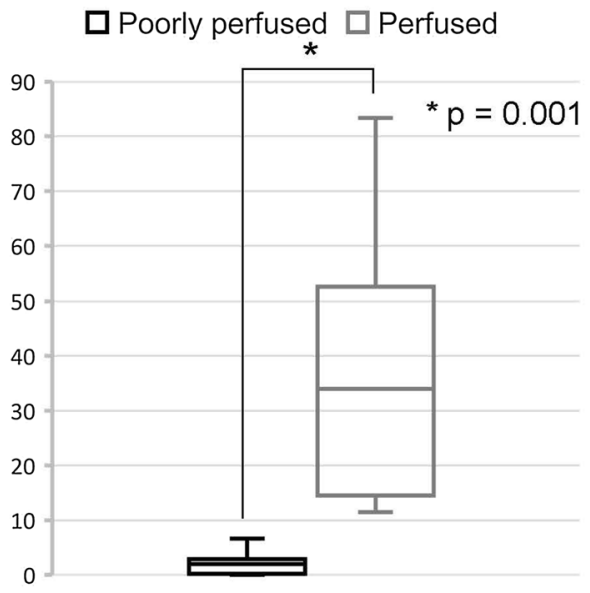

threshold of detection of ICG. Although contrast quantification showed a clear difference between the subjectively judged perfused and poorly perfused tissue, the ratios found in the group with poorly perfused tissue remain above the cutoff values described in the literature (a SBR above two is considered clinically and a CNR above three as statistically fluorescence enhanced [13]). This raises the question if the poorly perfused tissue might be adequately perfused, while subjective interpretation determines that the fluorescent dye is not visible. Currently the threshold of the amount of dye or signal for adequate perfusion of a pedicled omentoplasty is unknown. Further work is required to determine optimum sensitivity and threshold levels for the assessment of perfusion sufficiency, in particular with regard to omentum-related complications. A small number of studies have been performed to determine threshold levels by quantification of FA in animal and human studies, with promising findings that might guide future FA [14-16].

This study was limited by the relatively low number of patients and absence of patient outcomes. Therefore, although a high rate of change in management due to FA of a pedicled omentoplasty was found, no definitive conclusions can yet be drawn about its clinical relevance. To prove the potential added value of intra-operative fluorescence angiography, follow-up studies with a control group are warranted to compare clinical patient outcomes.

\section{Conclusions}

This single-center experience using FA to assess perfusion of a pedicled omentoplasty for filling of a pelvic cavity shows that the technique is feasible and readily achievable with minimal added operating time. The high rate of change in management due to FA indicates that larger studies should be conducted to determine the impact on patient outcome in this setting.

\section{Compliance with ethical standards}

Conflict of interest RH has an educational grant from Stryker (Stryker European Operations BV). The other authors declare that they have no conflict of interest.

Ethical approval The local ethics committee waived the need for ethical approval.

Informed consent Patients were informed about the study by letter, including an opt out form. No objection to participate in this study was received from all individual participants included in this study.

Open Access This article is distributed under the terms of the Creative Commons Attribution 4.0 International License (http://creativeco mmons.org/licenses/by/4.0/), which permits unrestricted use, distribution, and reproduction in any medium, provided you give appropriate credit to the original author(s) and the source, provide a link to the Creative Commons license, and indicate if changes were made.

\section{References}

1. Killeen S, Devaney A, Mannion M, Martin ST, Winter DC (2013) Omental pedicle flaps following proctectomy: a systematic review. Colorectal Dis 15(11):e634-e645

2. Yamamoto T, Mylonakis E, Keighley MR (2001) Omentoplasty for persistent perineal sinus after proctectomy for Crohn's disease. Am J Surg 181(3):265-267

3. Musters GD, Borstlap WA, Bemelman WA, Buskens CJ, Tanis PJ (2016) Intersphincteric completion proctectomy with 
omentoplasty for chronic presacral sinus after low anterior resection for rectal cancer. Colorectal Dis 18(2):147-154

4. Sloothaak DA, Buskens CJ, Bemelman WA, Tanis PJ (2013) Treatment of chronic presacral sinus after low anterior resection. Colorectal Dis 15(6):727-732

5. Schloericke E, Zimmermann M, Benecke C et al (2017) Surgical management of complicated rectovaginal fistulas and the role of omentoplasty. Tech Coloproctol 21(12):945-952. https://doi. org/10.1007/s10151-017-1657-1

6. Blok RD, de Jonge J, de Koning MA, van de Ven AWH, van der Bilt JDW, van Geloven AAW et al (2019) Propensity score adjusted comparison of pelviperineal morbidity with and without omentoplasty following abdominoperineal resection for primary rectal cancer. Dis Colon Rectum 62:952-959

7. John H, Buchmann P (1991) Improved perineal wound healing with the omental pedicle graft after rectal excision. Int J Colorectal Dis 6(4): 193-196

8. Poston GJ, Smith SR, Baker WN (1991) Retrocolic pelvic omentoplasty in abdominoperineal excision of the rectum. Ann R Coll Surg Engl 73(4):229-232

9. Keller DS, Ishizawa T, Cohen R, Chand M (2017) Indocyanine green fluorescence imaging in colorectal surgery: overview, applications, and future directions. Lancet Gastroenterol Hepatol 2(10):757-766

10. Coriddi M, Kenworthy E, Weinstein A, Mehrara BJ, Dayan JH (2018) The importance of indocyanine green near-infrared fluorescence angiography in perfusion assessment in vascularized omentum lymphatic transplant. J Surg Oncol 118:109-112
11. Nakashima Y, Saeki H, Yukaya T, Tsutsumi S, Nakanishi R, Sugiyama M et al (2016) Blood flow assessment with indocyanine green fluorescence angiography for pedicled omental flap on cervical esophagogastric anastomosis after esophagectomy. J Am Coll Surg 222(5):e67-e69

12. Tichauer KM, Samkoe KS, Sexton KJ, Gunn JR, Hasan T, Pogue BW (2012) Improved tumor contrast achieved by single time point dual-reporter fluorescence imaging. J Biomed Opt 17(6):066001

13. Hoogstins C, Burggraaf JJ, Koller M, Handgraaf H, Boogerd L, van Dam G et al (2019) Setting standards for reporting and quantification in fluorescence-guided surgery. Mol Imaging Biol 21(1):11-18

14. Diana M, Agnus V, Halvax P, Liu YY, Dallemagne B, Schlagowski AI et al (2015) Intraoperative fluorescence-based enhanced reality laparoscopic real-time imaging to assess bowel perfusion at the anastomotic site in an experimental model. Br J Surg 102(2):e169-e176

15. Wada T, Kawada K, Takahashi R, Yoshitomi M, Hida K, Hasegawa $S$ et al (2017) ICG fluorescence imaging for quantitative evaluation of colonic perfusion in laparoscopic colorectal surgery. Surg Endosc 31(10):4184-4193

16. Kudszus S, Roesel C, Schachtrupp A, Hoer JJ (2010) Intraoperative laser fluorescence angiography in colorectal surgery: a noninvasive analysis to reduce the rate of anastomotic leakage. Langenbeck's Arch Surg 395(8):1025-1030

Publisher's Note Springer Nature remains neutral with regard to jurisdictional claims in published maps and institutional affiliations. 